\title{
Maxwell A. Cameron, Eric Hershberg y Kenneth E. Sharpe (eds.), Nuevas instituciones de democracia participativa en América Latina: la voz y sus consecuencias, México, Flacso, 2012, 361 pp.
}

I

nspirado en la obra Exit, Voice and Loyalty (1970) de Albert O. Hirschman, sale a la luz el libro Nuevas instituciones de democracia participativa en América Latina: la voz y sus consecuencias. Los editores, Maxwell A. Cameron, Eric Hershberg y Kenneth E. Sharpe, se dieron a la tarea de convocar a un conjunto de connotados investigadores para examinar el estado actual de la democracia participativa en América Latina. En el prefacio, Warren señala que el rasgo distintivo de la obra es el enfoque teórico novedoso "asentado en datos empíricos" para "describir y evaluar las innovaciones participativas en América Latina". Maxwell A. Cameron, Eric Hershberg y Kenneth E. Sharpe escriben el capítulo "Voces y consecuencias: participación directa y democracia en América Latina", en el que argumentan que la inestabilidad de la democracia en la región se observa a través de la debilidad institucional en la rendición de cuentas, la fragilidad de las cortes, las élites cerradas en el sistema de partidos y la exclusión ciudadana de los sistemas políticos. 
Ante la ausencia de estatalidad democrática se han levantado voces ciudadanas para exigir rendición de cuentas, responsabilidad estatal y demandas por bienes públicos, por ello "este interés en la voz institucionalizada es, quizá, la característica distintiva de este libro y lo que hace diferente a la mayor parte de los trabajos disponibles en la materia" (p. 35).

El trabajo de Gisela Zaremberg "'O nos quemamos, o nos congelamos': sociedad y sistema de partidos en consejos de desarrollo municipal en América Latina" emprende un estudio comparativo para evaluar la calidad de la participación de "los Conselhos Municipais de Desenvolvimiento Rural (CMDR) en Brasil (Bahía, región sisalera), los Consejos Municipales de Desarrollo Rural Sustentable (CMDRS) en México (Oaxaca), los Gabinetes de Participación Ciudadana (GPC) en Nicaragua (Nueva Segovia y León); y los Consejos Comunales (CC) en Venezuela (Zulia)." (pp. 40-41). Como resultado de su investigación con enfoque de teoría de redes, Zaremberg nos presenta una tipología que ilustra la relación entre partidos y sociedad, en donde una sociedad civil o "popular" débil en sistema de partidos monopolizado crea una conexión de cooptación "simulada" como es el caso de Oaxaca (México), o bien "instrumental” como es el caso de Nuevo León (Nicaragua); por otra parte en una sociedad civil "fuerte", pero con sistema de partidos monopolizado se experimenta una participación de "movilización" como es el caso de Zulia (Venezuela); en el eje de sistema de partidos en "competencia" y sociedad débil con instrumentos de "votación" nos explica la autora que "no hay casos de nuestro estudio reflejados aquí"; finalmente en el eje de sistemas de partidos en competencia alojados en una sociedad civil fuerte se tiene el fenómeno de la "participación" como es el caso de Bahía (Brasil). La investigación de Zaremberg es la hoja de ruta para explicar estas nuevas voces de participación ciudadana en el ámbito municipal latinoamericano.

"Participación como representación: generación democrática de políticas públicas en Brasil" es el trabajo de Thamy Pogrebinschi. A partir del análisis de las conferencias nacionales de políticas públicas (CNP) en Brasil, celebradas entre 1988 y 2010, Pogrebinschi encuentra una participación activa de la sociedad civil en las propuestas de políticas públicas que fortalece los mecanismos de la democracia representativa al incidir en el rumbo de las políticas públicas en las áreas de "salud, minorías y derechos humanos, Estado, economía y desarrollo, y educación, cultura, seguridad social y deporte". La autora nos informa que $73 \%$ de las CNP durante el periodo de estudio señalado se dieron durante el gobierno de Lula Da Silva (20032010), lo que significa "un promedio de 9.2 conferencias por año durante sus ocho años de gobierno (llegando a un total de 74)" (p. 81). Pogrebinschi 
nos muestra que de 1988 a 2009 las "iniciativas e iniciativas constitucionales consistentes con directrices de CNP" reflejaron 19.8\% de iniciativas consistentes con CNP contra $80.2 \%$ de las no consistentes con CNP; por otra parte las iniciativas constitucionales consistentes con CNP fue de $48.5 \%$ contra las iniciativas constitucionales no consistente con CNP que fue de $51.5 \%$. Estos datos sobre la incidencia de la innovación participativa en los CNP y en la legislación nacional sostienen el argumento principal de la autora sobre el impacto de la amplia participación ciudadana en las propias instituciones representativas.

El trabajo "Participación acotada: consejos consultivos e incidencia en políticas públicas en el ámbito federal mexicano" de Felipe J. Hevia y Ernesto Isunza Vera presenta un detallado análisis organizacional de los consejos ciudadanos consultivos en México para concentrarse en el caso de los Consejos Consultivos de Desarrollo Sustentable (CCDS). Lo que llama la atención de los CCDS es su continuidad en el tiempo, así los autores identifican tres etapas de este proceso de participación en los CCDS entre 1995 y 2010: "la creación (1995-2000), el desafío de la continuidad (2001-2007) y la descentralización y articulación vertical (2008-2010)" (p. 113). El diagnóstico que plantean Hevia e Isunza Vera es que si bien es cierto que los CCDS han abierto la participación a una pluralidad de organizaciones no gubernamentales, ha prevalecido el manejo de una participación acotada debido, en parte, a la tradición corporativa en la política mexicana. No obstante, los CCDS "como instancias socioestatales, se han convertido en escuelas de ciudadanía donde los actores sociales y estatales generan dinámicas de relación que se desmarcan del corporativismo estatal, a pesar de lo acotado de la participación y de las intenciones de mayor incidencia” (p. 130).

Françoise Montambeault aborda en " $i$ Aprendiendo a ser 'mejores demócratas'? El papel de las prácticas informales en las experiencias de presupuestos participativos en Brasil" el tema del "aprendizaje cívico" en las prácticas informales de los ciudadanos en los procesos de los presupuestos participativos (PP) en Brasil, donde se concentra en un análisis comparativo de los casos de Belo Horizonte, Porto Alegre y Recife. Montambeault encuentra que las experiencias de los PP en Porto Alegre, Belo Horizonte y Recife "muestran distintos resultados de aprendizaje democrático a pesar de compartir diseños institucionales similares [reafirmando] la necesidad de ir más allá del análisis de las instituciones formales" (p. 149). En ese sentido, al estudiar las prácticas informales, Montambeault encontró que en Belo Horizonte y Porto Alegre el aprendizaje democrático construyó una ciudadanía con un sentido de "pertenencia" a la comunidad política y el discurso de un "nosotros" cuando se trataba de proyectos comunes. No 
obstante, en Recife se encontró la "política de siempre", donde no se halla un "sentido de pertenencia" con la comunidad como en Belo Horizonte y Porto Alegre. Así, el trabajo de Montambeault muestra y abre líneas de investigación sobre las prácticas informales y la educación democrática en el contexto de las nuevas voces de participación ciudadana.

Michael M. McCarthy escribe "Las posibilidades y los límites de la participación politizada: Consejos Comunales, coproducción y poder popular en la Venezuela de Chávez", en donde argumenta que los consejos comunales son "casos de coproducción entre el Estado y la sociedad", espacios en donde se da una intensa negociación política por los bienes públicos. Para ello McCarthy realizó una exhaustiva investigación de campo en tres municipios de Caracas. El autor se concentra en una visión "dinámica" entre sociedad y Estado a través de la coproducción "dinámica", dicho sea de paso, que no logra atrapar las "nociones tradicionales de ciudadanía y clientelismo". Su análisis sobre el proceso de coproducción le permitió observar la movilización "desde arriba" y "desde abajo" en el proyecto político de Hugo Chávez. Si bien es cierto que los consejos comunales funcionan para crear "poder popular" en dirección del chavismo, también es cierto que corre de manera paralela a una intensa participación ciudadana por atraer bienes públicos a las comunidades, que durante la democracia del "puntofijismo" estuvieron excluidas. Así, en su estudio McCarthy pone el acento en las complejidades organizacionales y políticas de los consejos comunales que reflejan una intensa participación de las voces antes excluidas por el sistema político bipartidista venezolano.

En “Democratización y participación ciudadana en El Salvador de posguerra" Karina Esther Grégori Méndez nos explica cómo a partir de los Acuerdos de Paz de 1992 El Salvador inicia su vida democrática a partir de sus primeras experiencias de participación ciudadana en las áreas en donde estaba asentado - en tiempos de guerra - el Frente Farabundo Martí para la Liberación Nacional (FMLN), antes un movimiento guerrillero, ahora un partido político. En ese sentido, su estudio atiende la experiencia de la participación ciudadana del municipio de San Salvador en el periodo 19972009 y en las experiencias participativas de los Comités de Desarrollo Local (CDL). Una observación relevante que nos indica Grégori es que el FMLN ha tenido una mayor vocación para estructurar las organizaciones de participación ciudadana que su contraparte, el partido conservador Alianza Republicana Nacionalista (Arena). De ahí que el auge de los mecanismos de la cultura participativa en el periodo 1994-1997 se deba en gran medida a la presencia política del FMLN. En San Salvador, la participación ciudadana empieza a decaer a partir de 2009 debido a la llegada a la presiden- 
cia de la Alcaldía Municipal de Norman Quijano de Arena. Sin embargo, a pesar de estos avances de cultura participativa "en el caso salvadoreño, la participación ciudadana se enfrenta a fuertes resistencias autoritarias arraigadas en la cultura política" (p. 230).

Alicia Lissidini en "Democracia directa en Uruguay y en Venezuela: nuevas voces, antiguos procesos" aporta un valioso estudio comparativo sobre mecanismos institucionales de democracia directa entre Uruguay, país con la "más larga tradición en Latinoamérica de democracia directa" (p.237), y Venezuela, país con una significativa legislación en la materia. En Uruguay hubo 24 consultas populares entre 1917 y 2009. Sobre el ejercicio de la democracia directa en Uruguay entre 1989 y 2009, la autora identifica cuatro tipos, a saber: "a) como herramienta para hacer justicia; b) para frenar las privatizaciones; c) como herramienta para la defensa de intereses sectoriales o corporativos; d) para modificar el diseño electoral" (pp. 246249). Para el caso de Venezuela, Lissidini registra las siguientes consultas populares: el referendo del 25 de abril de 1999 para la instalación de una Asamblea Nacional Constituyente; la consulta popular del 15 de diciembre de 1999 para una reforma constitucional de gran calado con miras a incluir derechos humanos y mecanismos de democracia directa y participativa; el referendo del 2 de diciembre para "la renovación de la dirigencia sindical por voto secreto"; la revocatoria del mandato presidencial de Hugo Chávez, celebrada el 15 de agosto de 2004, y las consultas populares para las reformas constitucionales del 2 de diciembre de 2007 y el 15 de febrero de 2009. Una de las reflexiones que nos presenta Lissidini al comparar los casos de Uruguay y Venezuela es: "más consultas, ¿más democracia?", su observación final es elocuente al respecto: "Mientras que en Uruguay el sistema de partidos y la cultura política obliga a los actores a buscar el consenso y las voces tienden a utilizarse de manera que se evita la salida, en el caso de Venezuela impera una lógica mucho más clientelar y menos democrática" (p. 269).

Todd A. Eisenstadt y Jennifer Yelle presentan el trabajo "Participación y representación en Oaxaca, elecciones por usos y costumbres: debates normativos y lecciones para el multiculturalismo latinoamericano". El estado de Oaxaca tiene 418 municipios - de un total de 570 - regidos por la participación electoral de usos y costumbres. En este contexto, la investigación de Eisenstadt y Yelle destaca puntos relevantes sobre la lógica de usos y costumbres, a saber: a) la presencia corporativa del PRI en estos municipios que se presta a la manipulación de las "reglas" de los usos y costumbres en los municipios oaxaqueños; $b$ ) la discriminación hacia las mujeres, que obstaculiza su participación política; c) la exclusión en la participación 
electoral por usos y costumbres a los migrantes, como es el caso del municipio de Santa Ana del Valle; d) Los conflictos postelectorales "severos" en los municipios con prácticas electorales de usos y costumbres. Así, los autores observan que existe una tensión entre las instituciones jurisdiccionales electorales, desprovistas de mecanismos legales para resolver conflictos postelectorales en municipios con el régimen electoral de usos y costumbres. No obstante, si la legislación sobre usos y costumbres busca una salida armoniosa para garantizar el voto universal en estos municipios, Oaxaca sería un modelo "más útil de instituciones parcialmente autónomas para lugares como Bolivia y otros movimientos de derechos indígenas en América Latina" (p. 302).

José Luis Exeni R. en "Esquiva demodiversidad en Bolivia: entre representación, participación y autogobierno" nos presenta una investigación sobre los novedosos arreglos institucionales en Bolivia a partir del análisis de la Constitución de 2009 en perspectiva comparada con la Constitución de 1967. La "esquiva demodiversidad" en Bolivia tiene innovaciones constitucionales construidas bajo el gobierno de Evo Morales, entre ellas podemos mencionar que el modelo constitucional de 2009 concibe al Estado de Bolivia como "comunitario" y "descentralizado y con autonomías" a la vez que se "transforma" en un Estado "plurinacional" e "intercultural". Asimismo, esta demodiversidad por el lado de la representación ratifica "la elección de representantes por voto universal, directo y secreto" (p. 315); por otra parte la democracia directa y participativa se expresará "por medio del referendo, la iniciativa legislativa ciudadana, la revocatoria de mandato, la asamblea, el cabildo y la consulta previa" (p. 315). En la "democracia comunitaria" el Estado de Bolivia: a) es un Estado plurinacional; b) garantiza la libre determinación; c) adopta la democracia directa, participativa, representativa y comunitaria; d) reconoce que "las naciones y los pueblos indígenas originario campesinos [...] podrán elegir, designar o nominar a sus autoridades y representantes mediante normas y procedimientos propios" (p. 321). A pesar de estos avances significativos la democracia en Bolivia se enfrenta a desafíos, pues "dijo adiós a lo que fue y se detiene en lo que será" nos dice el autor.

La obra colectiva aquí reseñada cierra con las reflexiones de Maxwell A. Cameron y Kenneth E. Sharpe en "La voz institucionalizada en las democracias de América Latina", en donde establecen un agudo debate normativo con la literatura sobre la consolidación democrática y la perspectiva crítica de los modelos de democracia liberal, cuyas investigaciones apuntan a poner el énfasis en las formas incompletas de la democracia en América Latina sin lograr atrapar las "nuevas voces institucionalizadas" en que se 
mueven - en ritmos diferentes - las formas democráticas de participación en la región. Para poder comprender los ricos matices de estas innovadoras voces institucionalizadas el libro viene a llenar ese gran vacío en la literatura sobre la democracia participativa en la región latinoamericana.

Noé Hernández Cortez* el Departamento de Administración Pública de la Universidad del Istmo, campus Ixtepec. 